Article

\title{
Climate Adaptability Construction Technology of Historic Conservation Areas: The Case Study of the Chinese-Baroque Historic Conservation Area in Harbin
}

\author{
Hong Jin ${ }^{1}$, Jing Zhao ${ }^{1}$, Siqi Liu ${ }^{1}$ and Jian Kang ${ }^{1,2, *(\mathbb{D})}$ \\ 1 Heilongjiang Cold Region Architectural Science Key Laboratory, School of Architecture, \\ Harbin Institute of Technology, Harbin 15000, China; jinhong@hit.edu.cn (H.J.); \\ jingzhao_hit@163.com (J.Z.); siqiliu@hit.edu.cn (S.L.) \\ 2 UCL Institute for Environmental Design and Engineering, The Bartlett, University College London (UCL), \\ Central House, 14 Upper Woburn Place, London WC1H0NN, UK \\ * Correspondence: j.kang@ucl.ac.uk; Tel.: +44-(0)20-3108-7338
}

Received: 23 August 2018; Accepted: 18 September 2018; Published: 20 September 2018

check for updates

\begin{abstract}
In recent years, the conflict between human activities and the natural environment has led to global warming and extreme weather, which has provoked people into thinking about the climate adaptability of buildings. Historical blocks are usually built and designed based on the social environment and climatic conditions at that time; therefore, they generally contain the construction techniques relevant to dealing with the local climate. The study aims to study the microclimate characteristics of a historic conservation area in a severe cold region and to explore how it attempted to achieve climate adaptation. Taking the Chinese-Baroque historic conservation area in Harbin as an example, this paper analyzed and studied the climate adaptability technology and excavated the suitable technology for the block to deal with a severe cold climate through research, field measurements, and numerical simulation. The results showed that compared with a certain modern urban area in the city, the Chinese-Baroque historic conservation area had better ability to resist wind and cold. The compact layout of the block could reduce heat loss and keep out the cold by effectively resisting the cold wind from permeating inside. Compared with the T-shaped and L-shaped courtyards, the rectangular courtyard occupies the largest proportion and a rectangular courtyard enclosed by buildings on all sides had better windbreak performance. Furthermore, when the courtyard space was enclosed by four sides and the courtyard width was the same, when the plane aspect ratio was smaller, the maximum wind speed of the inner courtyard was smaller. The squares in the block had a good performance in cold resistance. At the same scale, the higher the degree of enclosure of the square, the lower the internal wind speed. This study will provide a reference for urban planning and architectural design in severe cold regions.
\end{abstract}

Keywords: severe cold region; historical block; microclimate; climate adaptability technology

\section{Introduction}

In recent years, the conflict between human activities and the natural environment has led to global warming and extreme weather. Researchers have gradually begun to study the interaction between the city, architecture, and climate to find solutions. For example, researchers found that greenspace can improve the city's thermal environment [1]; the application of sustainable building equipment technology in buildings is conducive to energy conservation and emission reduction [2]. Thereto, the climate adaptability of buildings has also aroused researchers' wide consideration. Climate adaptability 
is often used to express the ability of buildings to resist, adapt to, and regulate natural climates. In this paper, climate adaptability mainly means that buildings produce an adaptation to climate change. It is an interactive process between the buildings and climate. It is of great significance for creating comfortable-to-use space, energy saving, and emission reduction to use appropriate climate adaptation technology in architectural design and block planning.

Studies showed that traditional architecture and settlements often reflect the concept of human adaptation to climate. For example, Johansson et al. conducted winter and summer thermal environment measurements in traditional and modern blocks in hot, arid regions, which showed that modern blocks' minimum temperature was $2-4{ }^{\circ} \mathrm{C}$ lower and the maximum temperature was $10^{\circ} \mathrm{C}$ higher than that of traditional blocks [3]. Afterwards, Johansson further compared the deep street of the traditional block with a shallow street of a modern block and found that the deep street was more comfortable in summer, while the shallow street valley could receive more sunlight in winter [4]. Indraganti conducted a climate adaptation study on typical traditional settlements in India. The relationship between settlements and climate from the layout of the settlements, the shape of the streets and courtyards, and the choice of building materials was explored. Also, the cooling effect of the centralized layout and narrow streets with high density in the conditions of a xerothermic climate was pointed out [5]. Dili et al. conducted a climate adaptation study on a typical inner-courtyard traditional residential building in the hot and humid climate of Southern India. The study found that the indoor thermal environment could be improved effectively through reasonable material selection and traditional method technology [6]. Nasrollahi et al. numerically simulated the thermal performance of traditional courtyards in the Shiraz region of Iran. Considering the orientation of the courtyard and the aspect ratio, it was found that a larger aspect ratio and south-facing courtyard had better shading effects in summer, more solar radiation in winter, and the ability to adjust wind speed, which could enable reaching an ideal thermal comfort level [7]. In addition, domestic scholars also conducted field measurements and simulated research on the physical environment of historical block squares, courtyards, and streets [8-11] to explore the climate adaptability of buildings and improve the performance of the architecture in light of its current problems.

The urban historic block is often a kind of urban open space, which plays an important role in reflecting the cultural diversity of the city and continuing the historical context of the city. Historic conservation areas with a good microclimate can provide natural, safe, comfortable, and pleasant space environments for urban residents. Therefore, the study of microclimate in historic conservation areas is very important for urban construction, the protection and development of urban history and culture, and the quality of life of urban residents. Through the literature survey of several historic conservation areas in China, it can be seen that the building form of historical blocks is often evolved from the traditional Chinese courtyard and the height of the building is mostly 1-3 stories, such as Broad and Narrow Alley in Chengdu and Three Lanes and Seven Alleys in Fuzhou. The Chinese-Baroque historic conservation area in Harbin has these basic characteristics. Historical blocks are usually built and designed based on the social environment and climatic conditions at that time; therefore, they generally contain the construction techniques relevant to dealing with the local climate. Therefore, taking the Chinese-Baroque historic conservation area in Harbin as an example, this paper expounds the climate adaptability of the spatial morphology of the historic blocks. The name 'Chinese-Baroque' was originally put forward by a Japanese scholar named Yasuhiko Nishizawa. Simply speaking, it is the 'Baroque' in China; that is, Baroque architecture with Chinese characteristics formed in China. Chinese-Baroque buildings in Harbin, Wuhan, Beijing, and many other cities have survived, and Harbin has the largest and most complete Chinese-Baroque building groups [12].

The Chinese-Baroque historic conservation area is located in the north-central area of Daowai district in Harbin. Figure 1a displays the location and surroundings of the block, and Figure $1 \mathrm{~b}$ displays an aerial view of the Chinese-Baroque block. The Daowai district is an old town with a history of more than 200 years. Its predecessor was a village named Fujiadian on the Songhua River. It is a natural village controlled by traditional culture. As a result of the construction of the Middle East Railway, 
a large number of people who braved the journey to the Northeast came to live here, which made it become the most populous area in Harbin.
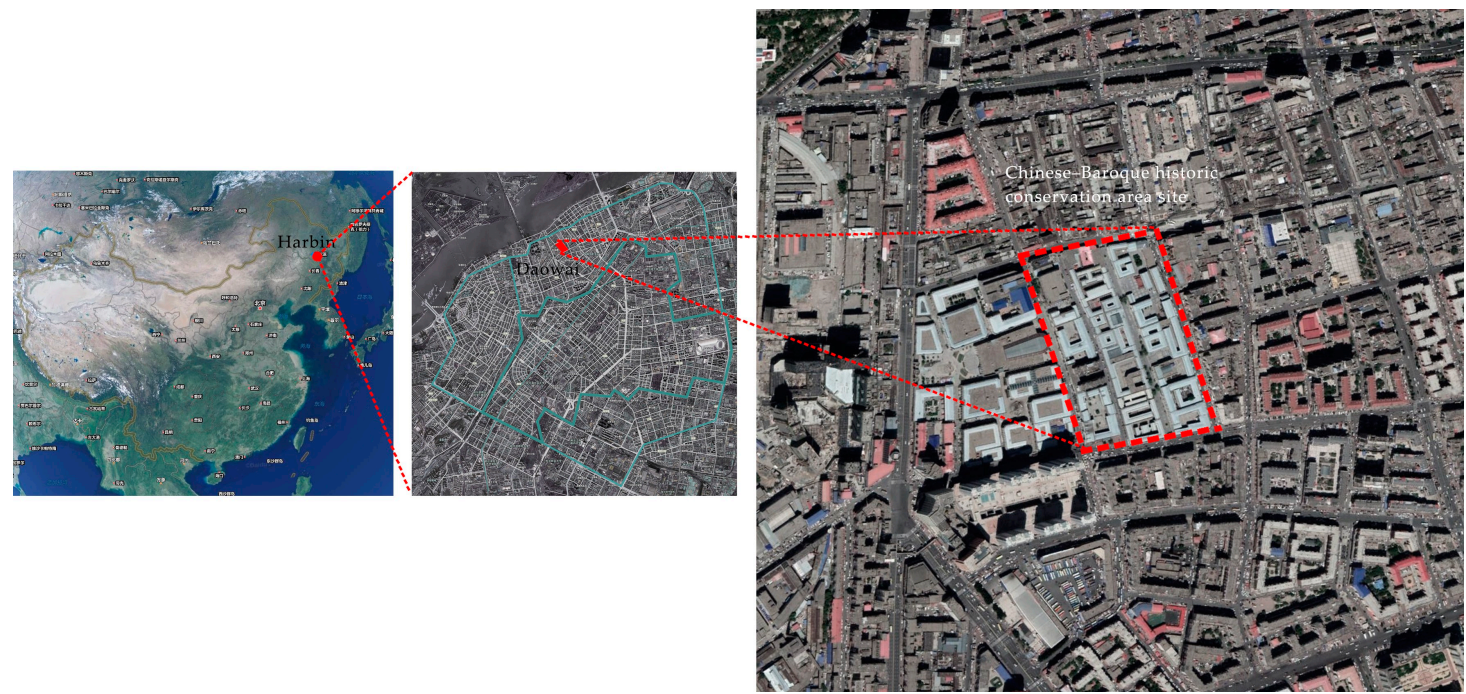

(a)

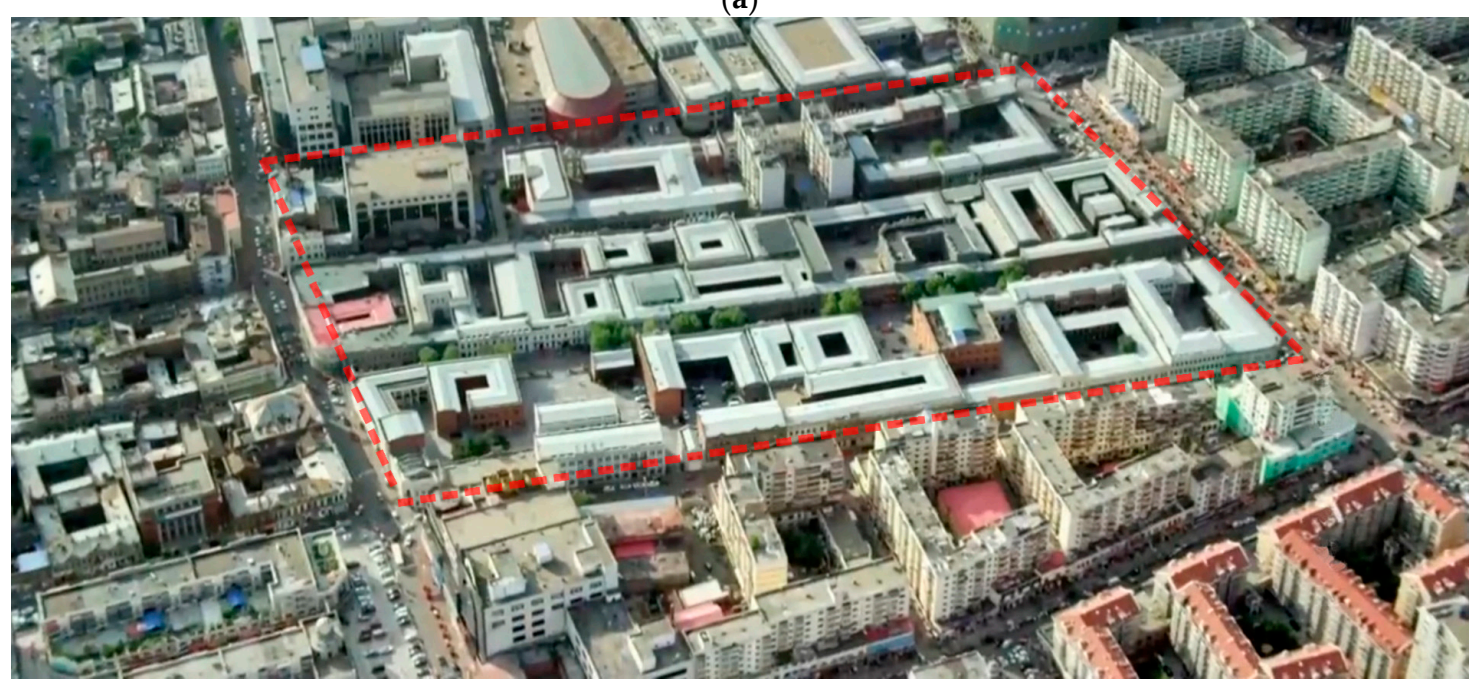

(b)

Figure 1. Location and aerial view of the Chinese-Baroque block. (a) Location and surroundings of the Chinese-Baroque block. (b) Aerial view of the Chinese-Baroque block [13].

These immigrants had deep-rooted traditional cultural roots and they had the needs of living together. Therefore, the overall residential form of the neighborhood followed the traditional courtyard-style layout of the Central Plains. After the rapid development of the foreign industry and commerce, combined with the climate characteristics of the severe cold region of Harbin, its layout form gradually developed into a courtyard mode of commercial and residential integration, and finally formed a layout of small neighborhoods and high building density [14]. In 2007, the protection and renewal of the "Chinese-Baroque block" was listed as a key project in Harbin and the Chinese-Baroque complex was repaired. The project aimed to repair the buildings and renovate the neighborhood environment with the goal of "repairing the old as before" [15]. In addition to the original street space and courtyard space, the square space was added. Although it changed, it basically maintained the texture of the original block.

Nowadays, the Chinese-Baroque historic conservation area in Harbin is one of the top ten historical and cultural protective blocks. It has the most intact Chinese-Baroque domestic architectural complex; tangible cultural resources such as distinctive courtyards, Hutong, etc.; and the intangible 
cultural resources of traditional business culture, culinary culture, and folk culture [15]. It is a product of integrating Chinese and Western cultures, which was designed and constructed based on the continuous cold climatic conditions in winter. Its unique block structure and spatial composition contains the construction methods and experience adapted to the local climate. Therefore, the study on the climate-adaptive construction techniques of the Chinese-Baroque historic conservation area is of great value for further exploring the excellent cold-adaptive design and construction techniques in traditional blocks and further providing references for urban construction in severe cold regions.

In summary, the current research on climate adaptive construction technology mostly focuses on xerothermic and hot-humid areas, thus there is a lack of relevant research on blocks in severe cold regions. At the same time, the research into the Chinese-Baroque historic conservation area in Harbin was mainly based on the exploration of architectural culture [16-20] as well as building protection and transformation [21-23]. Few researchers used climate as a breakthrough point to conduct research.

The study aims to study the microclimate characteristics of the historic conservation area and to explore how such a typical case attempted to achieve climate adaptation. Therefore, the research on the thermal environment characteristics of the block under the diversified space combination of the Chinese-Baroque historic conservation area in Harbin based on the climatic characteristics of the severe cold region was studied. By analyzing the field measurements of the thermal environment and the numerical simulation, the key technology to withstanding a severe cold climate was extracted to provide a reference for planning and architectural design in severe cold regions. In addition, as a typical historic block in cold regions, the study results can provide inspirations for the improvement of the similar type of blocks to create a more comfortable and pleasant public space environment in severe cold areas. Overall, the study of microclimate in the historic conservation area is important for urban construction, the protection and development of urban history and culture, and the quality of life of urban residents.

\section{Research Methods}

\subsection{Field Measurement}

In order to study the climate-adaptation technology of the Chinese-Baroque historic conservation area and establish whether it is superior to other regions, the field measurement method was applied to conduct a comparative test and analysis of the Chinese-Baroque historic conservation area and a certain area of the urban center. The specific measurement points were arranged as follows:

The Chinese-Baroque historic conservation area $\left(45^{\circ} 78^{\prime} \mathrm{N}, 126^{\circ} 64^{\prime} \mathrm{E}\right)$ was surrounded by Nanxun Street to the south, Jingyu Street to the north, South One Street to the west, and South Four Street to the east. There were 10 measuring points arranged in relation to the streets, squares, and courtyards, which covered the basic space types of the block. Four points, a1-a4, were located in three typical courtyards selected by their different forms and scale. Among them, a1 and a2 were located in the T-shaped courtyard and L-shaped courtyard, respectively; a3 and a4 were located in the same rectangular courtyard. b1 and b2 were placed on two small squares along the street, respectively. $c 1-c 3$ were placed on South Three Street; $\mathrm{c} 1$ and $\mathrm{c} 3$ were located at the square openings of the street and c2 was located in the facade continuity of the street. 44 was located at the facade continuity of the South Two Street. The sky view factor (SVF) of each measurement point was calculated using a fish-eye camera and RayMan software. The measuring point arrangement and measured photos are shown in Figure 2, and the information of each measuring point is shown in Table 1. 


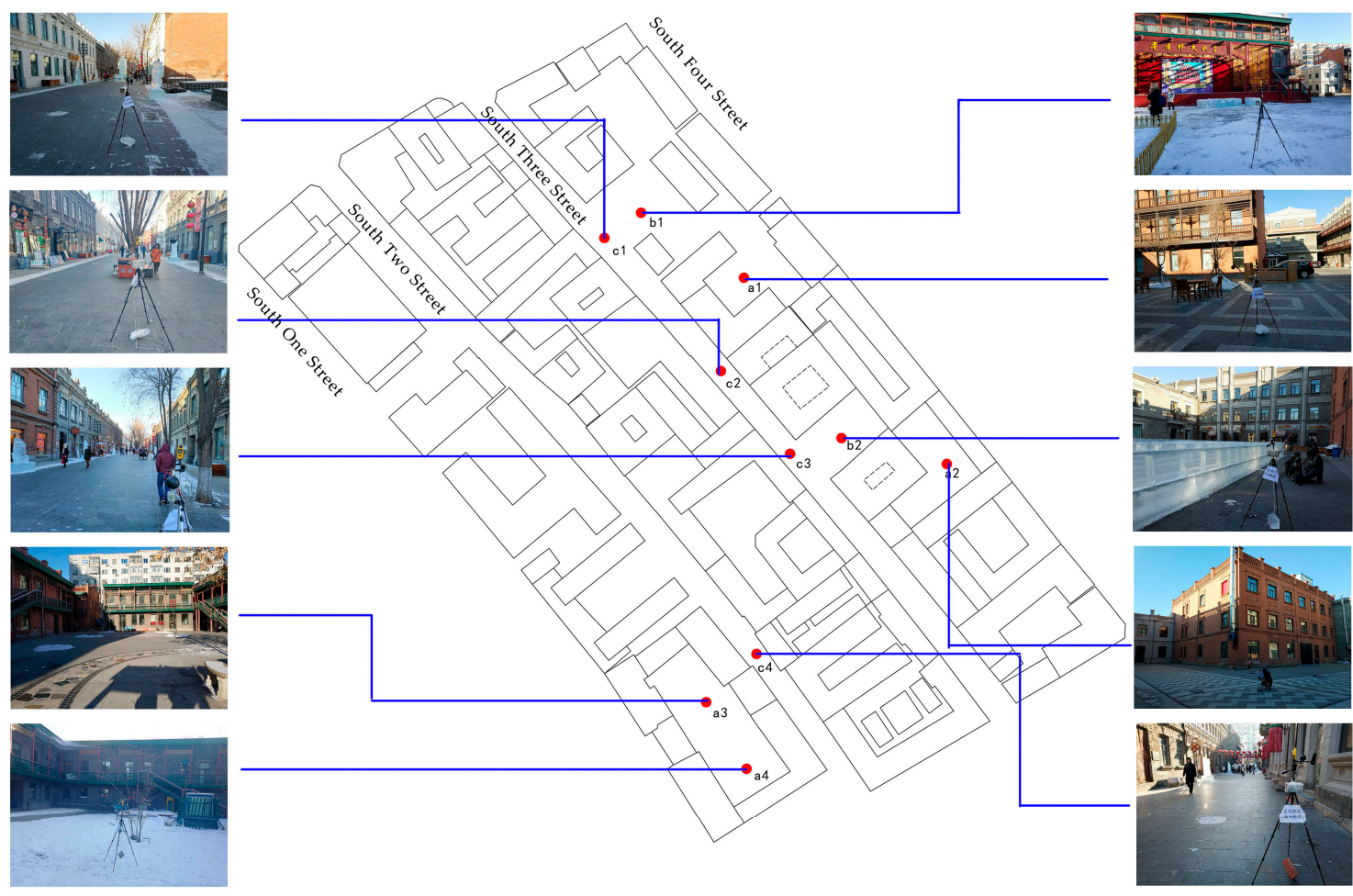

Figure 2. The arrangement of measuring points and measured photos.

Table 1. The information of each measuring point.

\begin{tabular}{|c|c|c|c|c|c|c|c|c|c|c|}
\hline Measuring Point & a1 & a2 & a3 & a4 & b1 & b2 & c1 & c2 & c3 & c4 \\
\hline $\begin{array}{l}\text { Height of building on both } \\
\text { sides }(\mathrm{m})\end{array}$ & 9 & 9 & 6 & 9 & 6 & 9 & 6 & 6 & 6 & 6 \\
\hline Street width $(\mathrm{m})$ & - & - & - & - & - & - & 42 & 12 & 47 & 10 \\
\hline Courtyard area $\left(\mathrm{m}^{2}\right)$ & $22 \times 37$ & $40 \times 40$ & $71 \times 26$ & $71 \times 26$ & $50 \times 30$ & $23 \times 35$ & - & - & - & - \\
\hline Street aspect ratio & - & - & - & - & - & - & $0 . \overline{143}$ & 0.5 & $0 . \overline{125}$ & 0.6 \\
\hline SVF of the measuring point & 0.695 & 0.624 & $0 . \overline{7} 02$ & 0.719 & $0 . \overline{783}$ & 0.656 & 0.738 & 0.622 & 0.627 & 0.540 \\
\hline
\end{tabular}

The study selected a reference point in the modern block of the city center and compared it with the microclimate of the Chinese-Baroque historic block in Harbin. The measuring point (hereinafter referred to as the reference point) was selected on the campus of the Harbin University of Technology, where the public space is composed of modern-scale buildings. In addition, there was a long-term weather monitoring point. Moreover, the weather station data from 27 December 2017 to 1 January 2018 were collected and the data on the test day were compared (the weather station data were downloaded from the China Meteorological Data Network [24]).

The measuring date in winter was on 27 December 2017 with temperatures of -24 to $-14{ }^{\circ} \mathrm{C}$, wind speed of $1.9-3.4 \mathrm{~m} / \mathrm{s}$, and wind direction of south-southwest $\left(202.5^{\circ}\right)$. Since the average temperature in the coldest month in Harbin was -24 to $-12{ }^{\circ} \mathrm{C}$ and the dominant wind direction in winter was south-southwest $\left(202.5^{\circ}\right)$, the weather on the test day could represent the typical climatic conditions in winter. During the test, thermal environment parameters such as air temperature and wind speed were measured. Air temperature and relative humidity were measured by a BES-02 temperature and humidity acquisition recorder (temperature measurement range of $-30-50{ }^{\circ} \mathrm{C}$, accuracy of $\pm 0.5{ }^{\circ} \mathrm{C}$; relative humidity measurement range of $0-99 \%$, accuracy of $\pm 3 \%$ ). The recorder was placed in a naturally ventilated radiation shield. The wind speed was measured by a Kestrel 5500 handheld small weather station (the wind speed measurement range of $0.4-40 \mathrm{~m} / \mathrm{s}$, accuracy of $\pm 0.1 \mathrm{~m} / \mathrm{s}$, and the wind direction measurement range of $0-360^{\circ}$, accuracy of $\pm 5^{\circ}$ ). Before the measurement, the instruments had been calibrated many times. Since the research was focused on the thermal 
environment at the height of the pedestrian, the test instruments were fixed on a tripod and placed at a height of $1.5 \mathrm{~m}$ from the ground. The time interval of test and data recording was $1 \mathrm{~min}$.

\subsection{Numerical Simulation}

The simulation analysis software adopts the ENVI-met. It can simulate the energy, momentum, and material exchange processes between buildings, the ground, vegetation, and the atmosphere in small-scale urban spaces with the function of calculating the wind field, turbulence, radiation, air temperature, and humidity, which is based on the related theories of fluid mechanics, thermodynamics, and urban meteorology. The ENVI-met model has a horizontal space size of $\leq 1.0 \mathrm{~km}$, a vertical space size of $\leq 200 \mathrm{~m}$, a spatial resolution of $0.5-10 \mathrm{~m}$, and a time resolution of 1-10 s [25]. Nowadays, ENVI-met has been widely used in urban microclimate research in different regions of the world, including by $\mathrm{Ng}$ et al. [26], Andreou et al. [27], and Li et al. [28]. Researchers are continuously verifying and proving the accuracy and effectiveness of ENVI-met simulation results for the outdoor environment [29].

The model was validated according to the field measurement data of the Chinese-Baroque historic conservation area. The measured model space was simplified and 10 points relative to the measured positions were selected. The meteorological parameters during the simulation were set as shown in Table 2. Figure 3a shows the pedestrian-level wind speed at each data collection point, where the point was at the same position in both the ENVI-met simulation and field measurements. Figure $3 \mathrm{~b}$ shows wind speed regression analysis of the field measurements and the ENVI-met simulations. By comparing the simulated wind speed to the measured data of each measuring point, it was found that although the wind speed values in the simulation results were $0.27-0.62 \mathrm{~m} / \mathrm{s}$ larger than the measured data, the numerical trend between the measuring points was basically the same. Besides, there was a linear correlation between the simulated values and the measured values $\left(R^{2}=0.7348\right)$. Because the surface roughness parameters are lower than in the actual test area, the simulated wind speed is higher. In the same time, ENVI-met can only simulate the situation in which the wind speed and direction remain unchanged; namely, it cannot simulate the wind field which changes with time. Moreover, the wind speed changes greatly when measured. These reasons led to the differences between the measured data and simulated data.

Table 2. Parameter settings for ENVI-met modeling.

\begin{tabular}{|c|c|}
\hline Model Size & \\
\hline Grid amount & $235 \times 235 \times 19$ \\
\hline Grid size & $2 \mathrm{~m} \times 2 \mathrm{~m} \times 3 \mathrm{~m}$ \\
\hline \multicolumn{2}{|l|}{ Meteorological Parameters } \\
\hline Simulation start time & 00:00 h, 27 December 2017 \\
\hline Total simulation time & $25 \mathrm{~h}$ \\
\hline Wind direction: & $202.5^{\circ}$ (Prevailing wind direction) \\
\hline Wind speed: & Wind speed is $2.7 \mathrm{~m} / \mathrm{s}$ at a height of $10 \mathrm{~m}$ \\
\hline Solar radiation intensity: & Calculated based on the conditions of sunny and cloudless weather \\
\hline Initial atmospheric temperature: & $-24.1^{\circ} \mathrm{C}$ \\
\hline Humidity: & $7 \mathrm{~g} / \mathrm{kg}$ (height of $2500 \mathrm{~m}$ ) \\
\hline
\end{tabular}




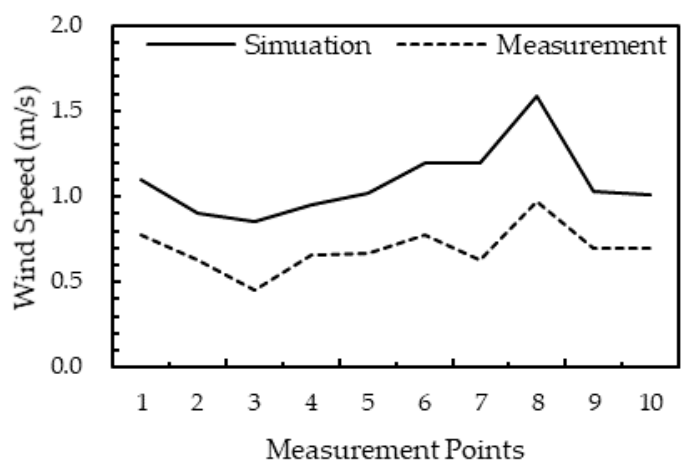

(a)

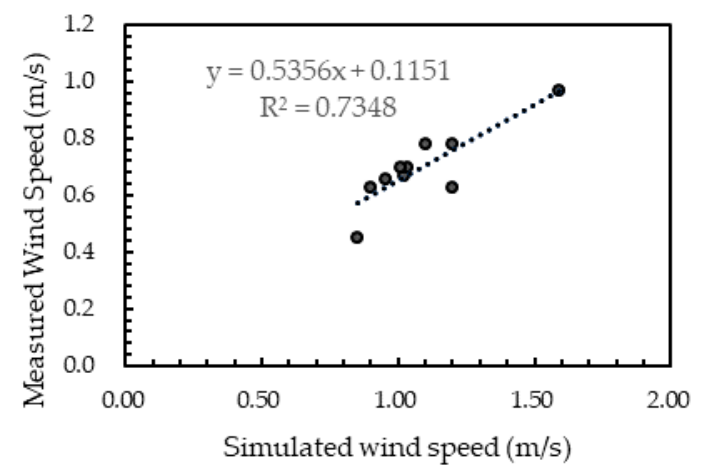

(b)

Figure 3. Comparison of wind speed between the field measurements and the ENVI-met simulations. (a) Comparison between the pedestrian-level wind speed results at each data collection point in the field measurements and the ENVI-met simulations. (b) Wind speed regression analysis of the field measurements and the ENVI-met simulations.

\section{Results}

Based on the geographical characteristics of severe cold regions, the Chinese-Baroque historic conservation area has an improved ability to keep the cold out of the blocks, starting with the layout, the spatial form, and the architectural form of the blocks. The coldproof technology of the compact block, the windproof technology of the enclosed courtyard, and the cold-adaptive technology of the square were three main technologies contributing to climate adaptability.

\subsection{Characteristics of the Space in the Chinese-Baroque Historic Conservation Area}

\subsubsection{The Block Layout}

The texture comparison between the Chinese-Baroque historic conservation area and the surrounding modern block is shown in Figure 4, which indicates that there is a certain difference between the layout of the two blocks. The architectural density of the Chinese-Baroque historic conservation area is about 0.55 and the width is $50-80 \mathrm{~m}$, whereas the density of modern block buildings is generally less than 0.40 and the width of part of the blocks will reach $400-500 \mathrm{~m}$. Compared with modern blocks, the Chinese-Baroque historic conservation area layout presents a compact and concentrated feature of high architectural density. The formation of the layout characteristics of the block are inseparable from the social environment and historical factors. At that time, the political and economic strength of the Daowai district was relatively weak. Therefore, the scale of the building was small and the building type was mainly for small and medium-sized commercial buildings and residential buildings [18]. In addition, the housing problem of the growing population needed to be solved, so the building density was high.

The Chinese-Baroque historic conservation area used the courtyard as the basic unit and the streets as the link. Courtyards of different sizes and shapes were arranged along the street to form a complete and continuous enclosure interface. The compact and dense enclosed layout can effectively defend against the cold wind in winter, obtain a relatively stable internal environment, and reduce heat loss in the building [14]. It plays the role of energy saving and emissions reduction. 


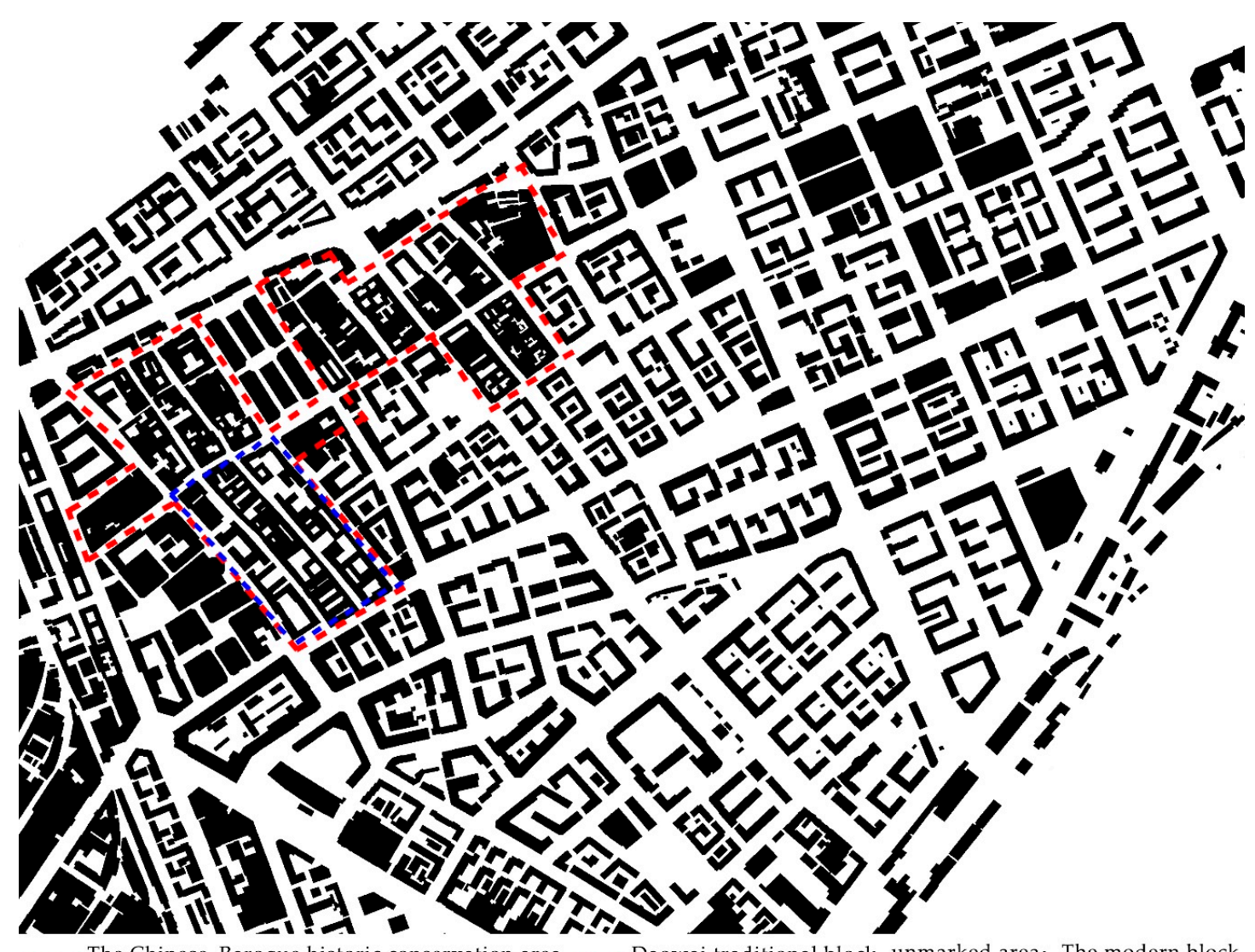

- = - The Chinese-Baroque historic conservation area = = =Daowai traditional block unmarked area: The modern block

Figure 4. The texture comparison between the Chinese-Baroque historic conservation area and the surrounding modern block.

\subsubsection{Courtyard Spatial Form}

As the main functional space of the Chinese-Baroque historic conservation area, the courtyard space carries certain activities and traffic functions, which evolved from traditional dwellings in the north. Figure 5 shows the pedestrian flow lines and the photo of each public courtyard. The function distribution of each courtyard in the block is shown in Figure 6a.

The evolution of courtyard morphology is a spontaneous organic growth mode. It takes the traditional northern courtyard as the space prototype. With the increasing space demand and complexity, it presents the superposition form from the triple courtyard, the quadrangle courtyard connected to the courtyard suite, and the courtyard-connected courtyard [20]. According to the flat shape, it can be divided into a rectangular shape (the building is enclosed on four sides, and the courtyard space is rectangular with different shapes of different aspect ratios), T-shape (the three directions of the building are connected together, and there are multiple forms due to the opening orientation), and L-shape (horizontal and vertical buildings are connected, usually combined with other courtyards and buildings; there are multiple forms due to the orientation of the opening). The distribution of various courtyards in the block is shown in Figure 6b. The proportion of rectangular courtyards, T-shaped courtyards, L-shaped courtyards, and other is $63 \%, 10 \%, 17 \%$, and $10 \%$, respectively. The courtyards in the block are enclosed by commercial buildings of $2-3$ stories, which are closed inwards. In addition, the courtyards have 2-5-m wide door openings which connect the courtyards to the street space. The enclosed form by multifaceted buildings of the courtyard space can effectively keep out the cold wind, while the transparent top interface is both a vent and an entrance for incoming sunlight. 

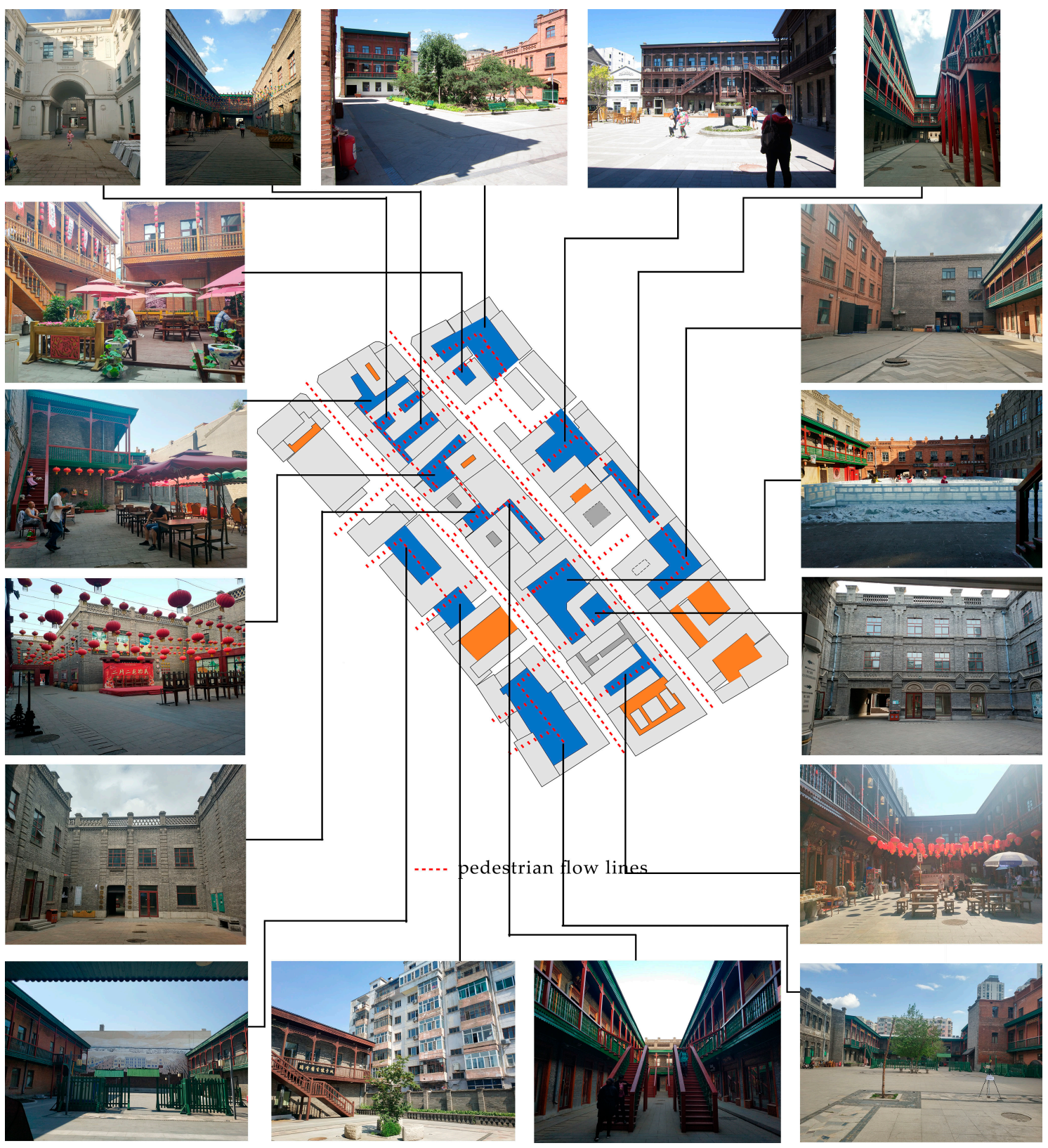

Figure 5. The pedestrian flow lines and the photo of each public courtyard.

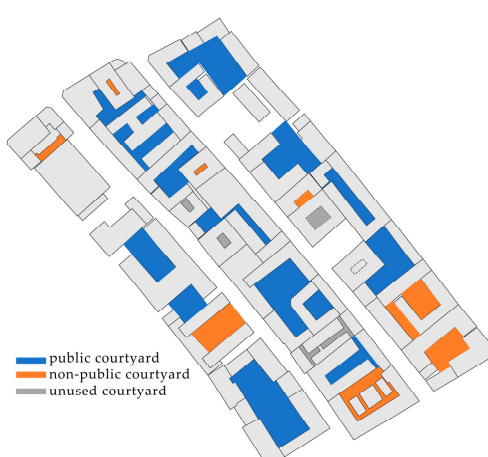

(a)

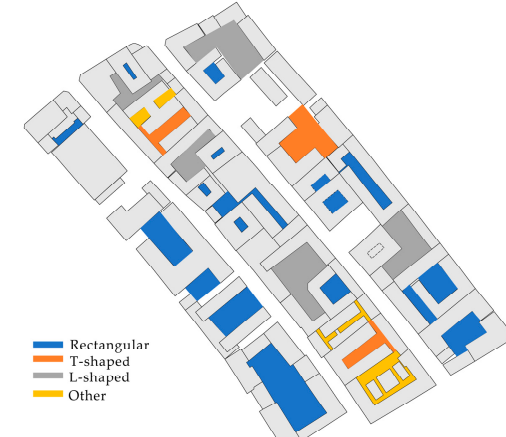

(b)

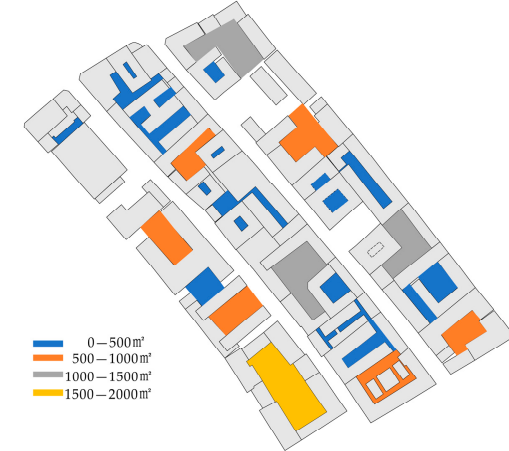

(c)

Figure 6. The distribution of the courtyard in the block. (a) The functional distribution. (b) Distribution of various courtyard shapes. (c) Distribution of courtyards' area. 
In addition, it can be seen from the texture map of the whole block that the courtyard size of the whole block varied from $40 \mathrm{~m}^{2}$ to $1800 \mathrm{~m}^{2}$. The distribution of courtyards' area in the block is shown in Figure $6 \mathrm{c}$; the proportion of courtyards whose area is less than $500 \mathrm{~m}^{2}$ is the highest, at $67 \%$. The plane dimension is quite different from the dimension of the courtyards in Harbin Modern Street. The yard space of the block is relatively small, with a strong style of enclosure and strong wind resistance.

\subsubsection{Space Features of the Square}

The square in the block is a place for people to rest, play, and perform. The square scale is limited by the width of the block, so it is similar to the yard space scale in the block. The dimensions of the two squares were $50 \mathrm{~m} \times 30 \mathrm{~m}$ and $23 \mathrm{~m} \times 35 \mathrm{~m}$, respectively. Through the research of 30 city squares in Harbin, such as the church square, memorial square, and traffic square, it was found that other squares in the city generally had three or four sides with street frontage, of which $63 \%$ of the squares were not enclosed by any building. Table 3 displays the comparison between the representatives of each enclosed square from the surveyed city squares and the Chinese-Baroque squares. It can be seen that the enclosure degree of the squares in the Chinese-Baroque historic conservation area was different from the other squares in the city. The squares of the block are semienclosed and surrounded on three sides by 2-3-story buildings and with one side along the pedestrian street. The square located on South Three Street near Jingyu Street is an open-type frontage square, of which the enclosed buildings are separated by a certain distance and are not completely connected. The central square of South Three Street is an enclosed frontage square whose enclosed buildings are completely connected. The relatively enclosed square space formed by the three sides of the block building makes it unique in terms of adapting to the cold climate when compared to other squares in the city.

Table 3. The comparison between the representatives of each enclosed square from the surveyed city squares and the Chinese-Baroque squares.

\begin{tabular}{|c|c|c|c|c|}
\hline Square & Enclosing Style & Area $m^{2}$ & Plane & Photo \\
\hline $\begin{array}{c}\text { Chinese-Baroque } \\
\text { square } 1\end{array}$ & $\begin{array}{l}\text { Three sides of } \\
\text { building enclosure }\end{array}$ & About 1500 & & \\
\hline $\begin{array}{c}\text { Chinese-Baroque } \\
\text { square } 2\end{array}$ & $\begin{array}{l}\text { Three sides of } \\
\text { building enclosure }\end{array}$ & About 800 & & \\
\hline $\begin{array}{l}\text { The Memorial } \\
\text { Tower of Fighting } \\
\text { Against the } \\
\text { Floods square }\end{array}$ & $\begin{array}{l}\text { No building } \\
\text { enclosure }\end{array}$ & About 13,000 & & \\
\hline
\end{tabular}


Table 3. Cont.

\begin{tabular}{ccccc}
\hline Square & Enclosing Style & Area $\mathrm{m}^{2}$ & Plane \\
\hline $\begin{array}{c}\text { Beer Culture } \\
\text { square }\end{array}$ & $\begin{array}{c}\text { One side of } \\
\text { building enclosure } \\
\text { and three sides of } \\
\text { frontage road }\end{array}$ \\
$\begin{array}{c}\text { Sophia Church } \\
\text { square }\end{array}$ & $\begin{array}{c}\text { Two sides of } \\
\text { buildings, two } \\
\text { sides of the road }\end{array}$ & About 22,000 & Photo \\
\hline
\end{tabular}

\subsection{Performance of the Climate Adaptation Technology in Chinese-Baroque Historic Conservation Area}

\subsubsection{The Coldproof Technology of the Compact Block}

To study the windproof and coldproof abilities of the compact layout of the block, the thermal environment of a typical space in the block was compared with the open space of the modern city block (reference point). Figure 7a shows the hourly variation of wind speed and air temperature at Harbin Meteorology Station from 27 December 2017 to 1 January 2018. Figure 7b shows the hourly comparison between the measured wind speed and air temperature of two blocks and the date from the meteorology station (the RP in the figure represents reference point and MS represents meteorology station). Table 4 lists the daily average wind speed and air temperature of each measurement point. It can be seen that the maximum wind speed at the weather station was $2.80 \mathrm{~m} / \mathrm{s}$ and the average daily wind speed was $2.16 \mathrm{~m} / \mathrm{s}$ higher than the reference point and the Chinese-Baroque block. The air temperature of the weather station decreased during the day, and the daily average air temperature was $-20.02{ }^{\circ} \mathrm{C}$. As can be seen from Figure $7 \mathrm{a}$, the daily air temperature of the meteorology station shows a downward trend from 09:00 $\mathrm{h}$ to 17:00 $\mathrm{h}$, and so does the test day. However, the air temperature curve of reference points and all points of the block shows an upward trend. The variation trend was different from that of the reference point and the Chinese-Baroque block. This is because urban meteorology stations are located in the suburbs, while the reference points and Chinese-Baroque block are located in the cities, and the microclimate is influenced by building form and scale.

In addition, the wind speed change in the Chinese-Baroque block was gentle, and that wind speed was significantly smaller than at the reference point. Its average daily wind speed was $1.09-1.61 \mathrm{~m} / \mathrm{s}$ lower than at the reference point. The air temperature in the block was significantly higher than at the reference point, and the daily average air temperature was $0.49-1.49^{\circ} \mathrm{C}$ higher than at the reference point. However, it was different from the change trend of the reference point. Therefore, this can prove that the Chinese-Baroque block showed a better performance in wind and cold resistance than the modern city block. 

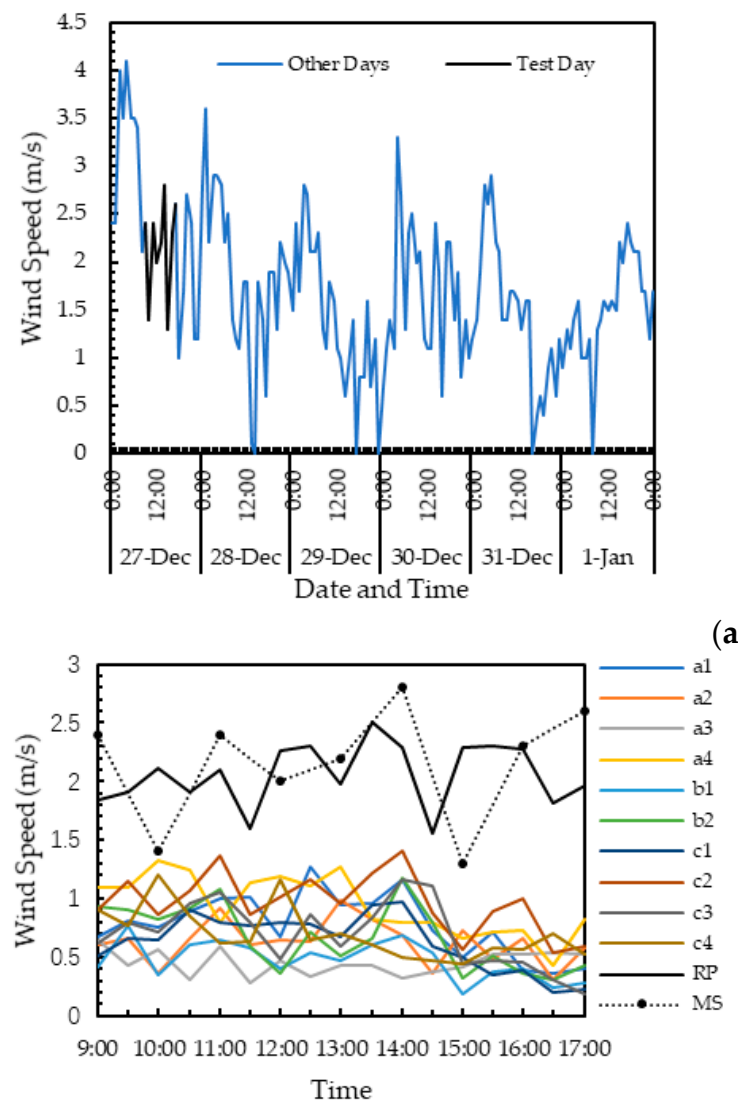

(b)

(a)
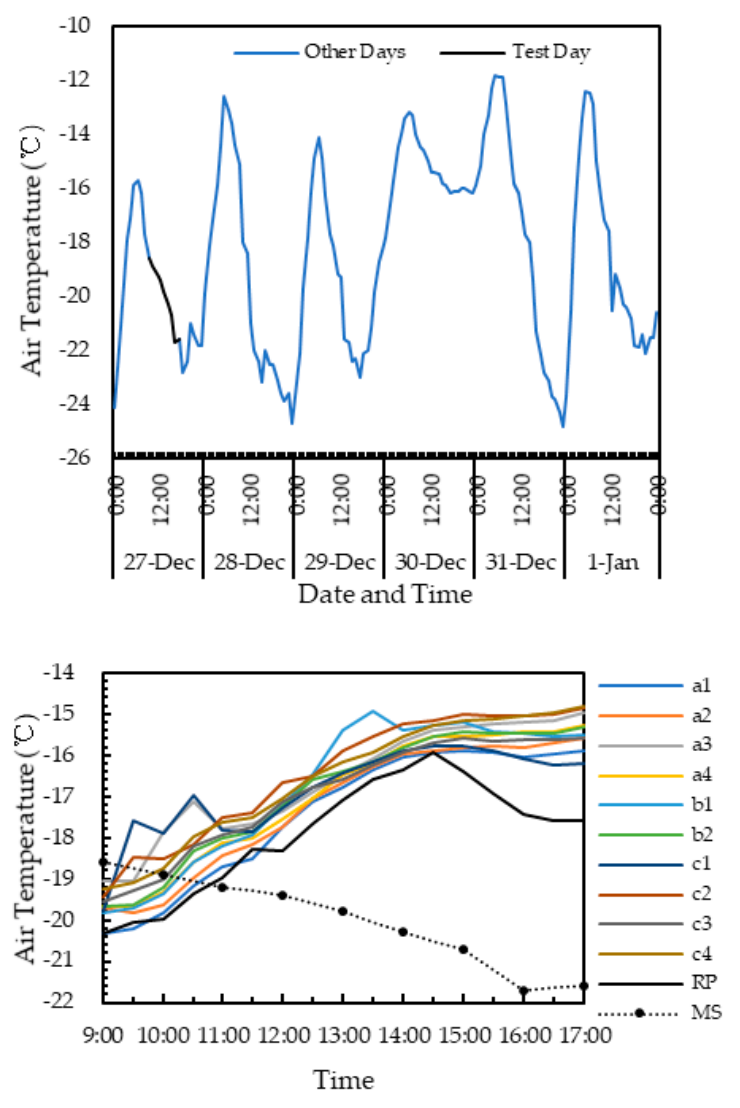

Figure 7. The hourly variation of measured wind speed and air temperature. (a) The hourly variation of wind speed and air temperature at the meteorological station from 27 December 2017 to 1 January 2018 (Black line represents 9:00-17:00 of test day and blue line represents other periods); (b) The hourly comparison of measured wind speed and air temperature between the block, reference point, and meteorology station (The RP in the figure represents reference point and MS represents meteorology station.).

Table 4. Measured daily average of each measuring point.

\begin{tabular}{|c|c|c|c|c|c|c|c|c|c|c|c|}
\hline Measuring Point & a1 & a2 & a3 & a4 & b1 & b2 & c1 & c2 & c3 & c4 & $\begin{array}{c}\text { Reference } \\
\text { Point }\end{array}$ \\
\hline Daily average wind speed, $\mathrm{m} / \mathrm{s}$ & 0.78 & 0.63 & 0.45 & 0.94 & 0.48 & 0.67 & 0.63 & 0.97 & 0.70 & 0.70 & 2.06 \\
\hline $\begin{array}{l}\text { The value difference between the } \\
\text { daily average wind speed and the } \\
\text { reference point, } \mathrm{m} / \mathrm{s}\end{array}$ & 1.28 & 1.43 & 1.61 & 1.12 & 1.58 & 1.39 & 1.43 & 1.09 & 1.36 & 1.36 & 0 \\
\hline Daily average Temperature, ${ }^{\circ} \mathrm{C}$ & -17.44 & -17.24 & -16.60 & -17.01 & -16.79 & -16.91 & -16.85 & -16.44 & -16.95 & -16.58 & -17.93 \\
\hline $\begin{array}{l}\text { The value difference between the } \\
\text { daily average temperature and the } \\
\text { reference point, }{ }^{\circ} \mathrm{C}\end{array}$ & 0.49 & 0.69 & 1.33 & 0.92 & 1.14 & 1.02 & 1.08 & 1.49 & 0.98 & 1.35 & 0 \\
\hline
\end{tabular}

\subsubsection{The Windproof Technology for Enclosed Courtyards}

Figure 8 shows the hourly comparison of measured wind speed and air temperature between the courtyard and reference point. It can be seen from the field measurements that the fluctuation of wind speed in the courtyard space of the Chinese-Baroque block was smaller than at the reference point. It indicates that the courtyard space of the Chinese-Baroque block was relatively stable and the daily average wind speed was $1.12-1.61 \mathrm{~m} / \mathrm{s}$ lower than at the reference point. The daily average air temperature in each courtyard of the block was $0.49-1.33{ }^{\circ} \mathrm{C}$ higher than at the reference point. It showed that the courtyard space form of the Chinese-Baroque area had a good ability to keep out the wind and cold. 

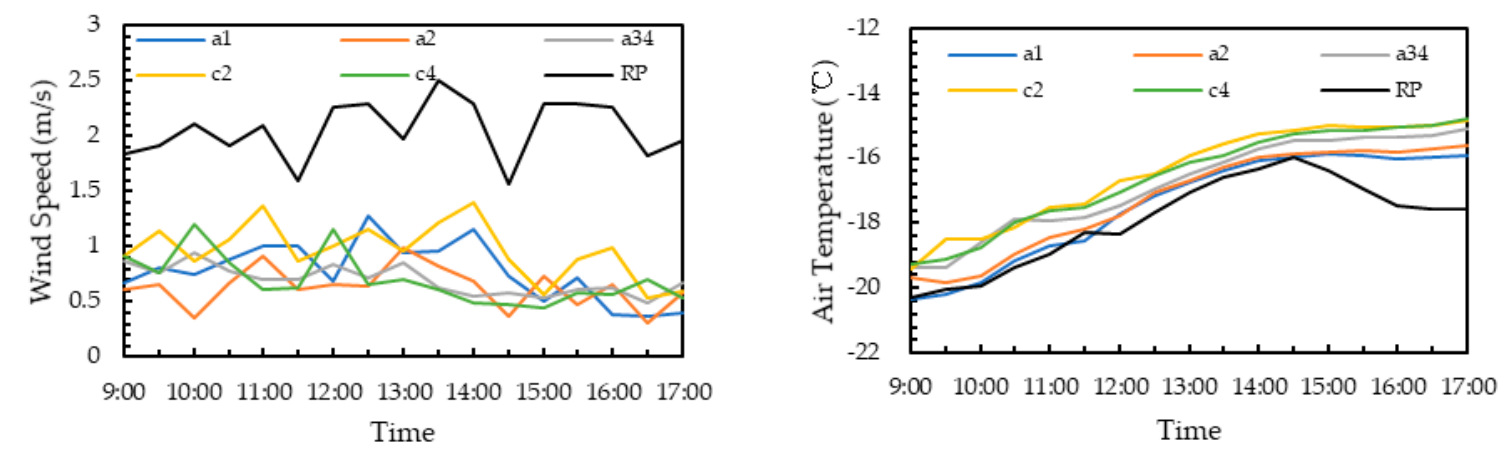

Figure 8. The hourly comparison of measured wind speed and air temperature between the courtyard and reference point.

In addition, in the measured comparison between the courtyard space and the street space in the block, it was found that the wind speed of the block could be ranked thus: in the street space (c2) > in the T-shaped courtyard space (a1) > in the L-shaped courtyard space (a2). The wind speed of the street, c4, and rectangular courtyard, a34 (since the rectangular courtyard area was larger, we used the average of a3 and a4 to represent the rectangular courtyard), were similar most of the time. In general, the wind speed of the courtyard was lower than the wind speed of the adjacent street. From this result, it can be seen that the enclosed form of the courtyard was beneficial in reducing wind speed and had better wind resistance in the tested (prevailing) wind direction and the scale of the courtyard. The daily average temperatures of the T-shaped (a1), L-shaped (a2), and rectangular (a34) courtyards were $-17.44{ }^{\circ} \mathrm{C},-17.24^{\circ} \mathrm{C}$, and $-16.81^{\circ} \mathrm{C}$, respectively. The air temperature of the rectangular courtyard was higher than that of the other two courtyards, so the cold-proofing performance of the rectangular courtyard was better.

The spatial shape of each courtyard was simulated to further study the windbreak performance of different forms of courtyards. In order to facilitate the comparative analysis, the windbreak performance of different forms of courtyards were compared and analyzed on the premise. Presented here are several ideal models in different forms. Regardless of the influence of different forms on the existing block environment, the study only considered the impact of the courtyards themselves. It indicated that the courtyard land area was fixed. The courtyard area was taken as the average courtyard area size in the block and set to $60 \mathrm{~m} \times 46 \mathrm{~m}$, the building height was $9 \mathrm{~m}$, the orientation was $40^{\circ}$ north to the west, and the meteorological parameter setting was the same as in Table 2.

Figure 9a shows the simulation speed cloud map of the courtyard wind environment, and Figure $9 \mathrm{~b}$ shows the maximum and average wind speeds for each simulation working condition. It can be seen that the difference in wind speed of the rectangular courtyard space was the smallest, the overall wind speed was lower, and the maximum wind speed was only $0.75 \mathrm{~m} / \mathrm{s}$. The opening of the T-shaped courtyard towards the north side (T1) had $0.1 \mathrm{~m} / \mathrm{s}$ lower average wind speed than towards the south side (T2). In addition, when the opening was towards the north side, the wind speed was significantly smaller than that at the south side. The average wind speed of the opening of the L-shaped courtyard towards the northeast side (L1) and the southwest side (L4) was lower than that towards the southeast side (L2) and the northwest side (L3). Therefore, compared with the L-shaped and T-shaped courtyard formed through an opening on one side or both sides, the rectangular courtyard enclosed by buildings on all sides had better windbreak performance.

It can be concluded that the enclosed structures of several courtyards in the block had good windbreak ability, but under the same land area, the rectangular courtyard with a higher degree of enclosure had a stronger windbreak performance. The block presented a variety of courtyard forms, and rectangular courtyards accounted for the highest proportion, which not only satisfied people's pursuit of spatial diversity, but also reflected the adaptability of the courtyard design to the cold climate. 


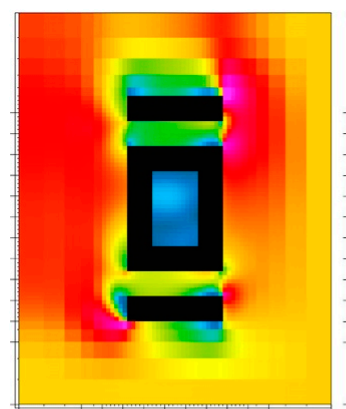

Rectangular

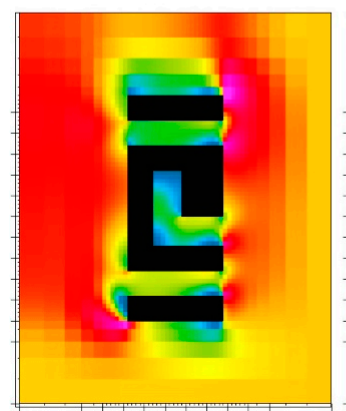

L2

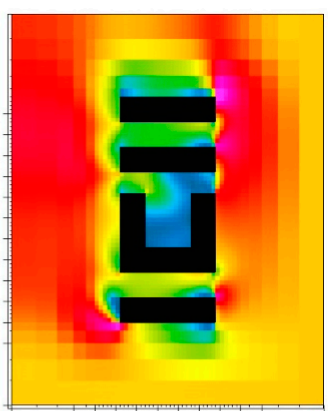

$\mathrm{T} 1$

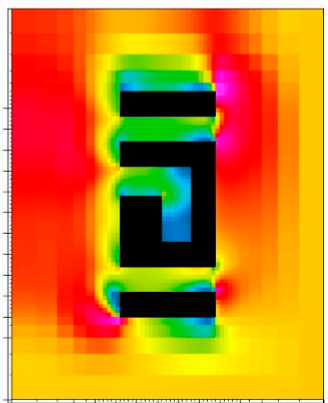

L3

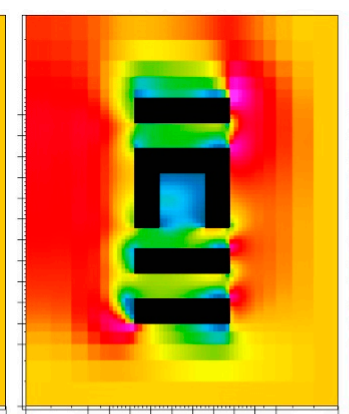

$\mathrm{T} 2$

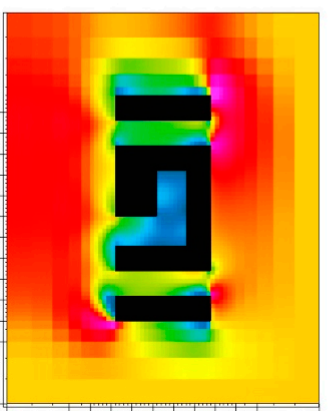

L4

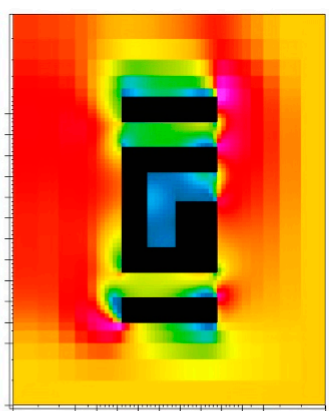

L1

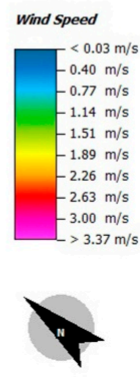

(a)

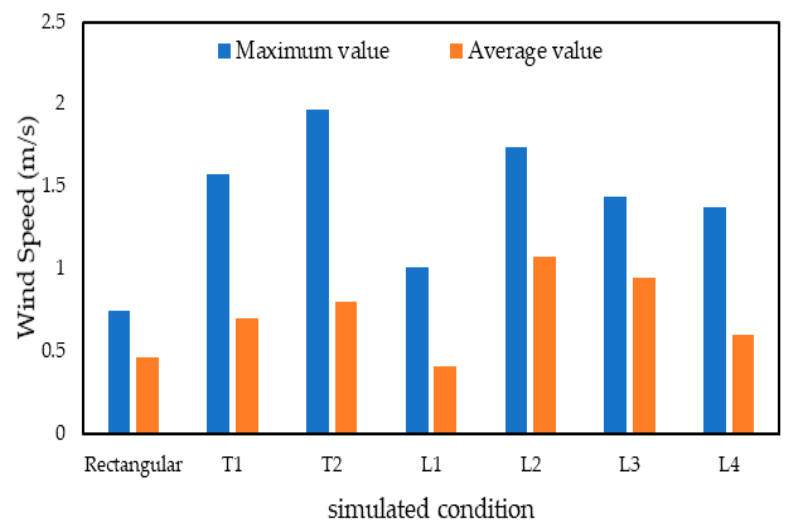

(b)

Figure 9. Simulation results of the courtyard wind environment (T1 and $\mathrm{T} 2$ respectively indicate the opening of the T-shaped courtyard towards the north side and the south side. L1, L2, L3 and L4 respectively indicate the opening of the L-shaped courtyard towards the northeast side, the southeast side, the northwest side and the southwest side). (a) Wind speed cloud map. (b) Maximum and average wind speeds for each working condition.

In addition, there were many rectangular courtyards in the Chinese-Baroque block with varied scales. However, based on the width of the block, the aspect ratios of the courtyards can be roughly divided into 1.5:1, 1:1, 0.75:1, 0.5:1, 1:0.5. 1.5:0.5, 1:0.5, 0.75:0.5, and 0.5:0.5. Taking the combination of courtyards in the block into account, wind environment simulations were carried out on courtyards of different scales on a block with a width of $60 \mathrm{~m}$ and a length of $180 \mathrm{~m}$. The wind speed simulation results of different courtyard sizes are shown in Figure 10. It can be seen that with the same width, the larger aspect ratio of the courtyard will lead to a larger internal maximum wind speed. On the whole, the larger the courtyard area, the larger the internal maximum wind speed, and as the 1.5:1 courtyard area was the largest, its wind speed was significantly larger than other courtyards. It can be seen that when the courtyard space was enclosed by four sides, the smaller the aspect ratio of the courtyard plane, the smaller the courtyard area, and the smaller the maximum wind speed of 
the inner courtyard was; that is, showing a stronger resistance of the courtyard to the outdoor wind. The courtyard in the block was composed of a variety of courtyards and the area was generally less than $500 \mathrm{~m}^{2}$. Only 1-2 courtyards were approximately $1.5: 1$, which also reflected its adaptability to climate.

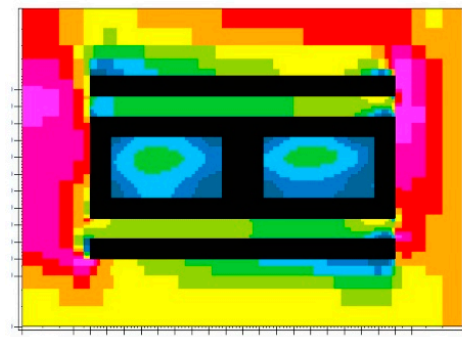

$1.5: 1$

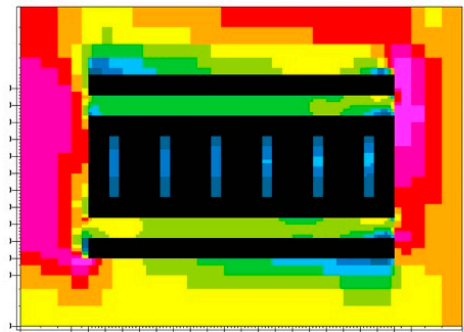

$0.5: 1$

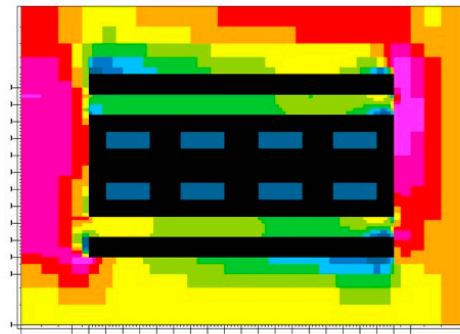

0.75:0.5

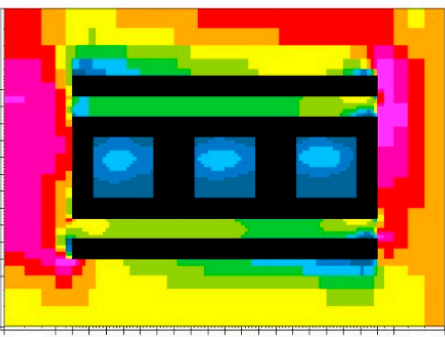

$1: 1$

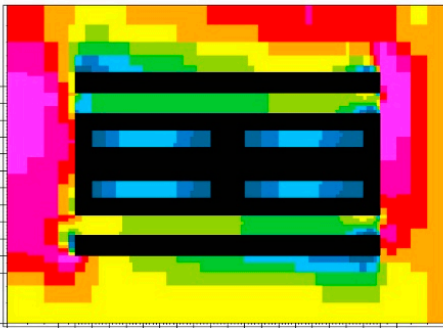

$1.5: 0.5$

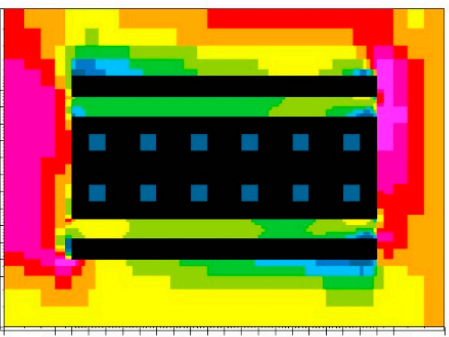

$0.5: 0.5$

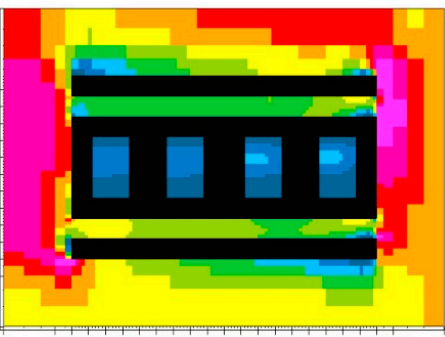

$0.75: 1$

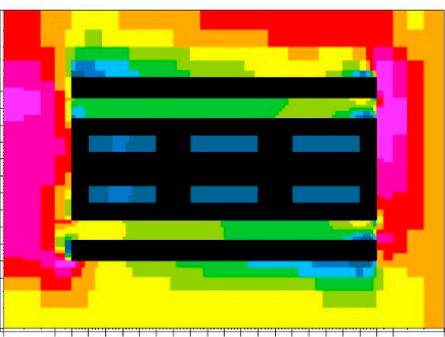

$1: 0.5$

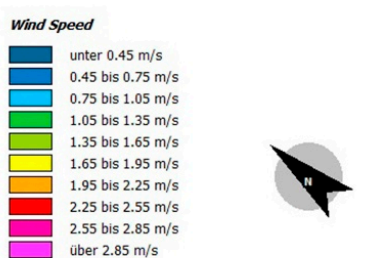

Figure 10. The wind speed simulation results of different courtyard sizes (shown as aspect ratio).

From the above, the enclosed structure and scale design of the courtyards of the block presented a better performance in dealing with the cold wind in winter and can provide a more comfortable outdoor space environment for the public.

\subsubsection{The Cold-Adaptive Technology of the Square}

A comparison between the block and the reference point for wind speed and temperature was conducted in order to study the climate adaptability of the square space in the block. Figure 11 shows the hourly comparison of measured wind speed and air temperature on the square and adjacent streets. It was found that the wind speeds of the two squares in the block were lower than the reference point; the daily average wind speed was lower than at the reference point by $1.58 \mathrm{~m} / \mathrm{s}$ and $1.39 \mathrm{~m} / \mathrm{s}$, respectively. The temperature was higher than at the reference point, and the daily temperature was $1.14{ }^{\circ} \mathrm{C}$ and $1.02{ }^{\circ} \mathrm{C}$ higher than at the reference point, respectively. It showed that the square space of the block had a good ability to protect against wind and cold. In addition, the wind speed of the two squares in the block was lower than that of the adjacent streets, which also showed that the enclosed style of the square is beneficial to lessen the influence of cold wind in winter.

In order to further investigate the climate adaptability of the square space, the square was set in different locations in the block and the degree of enclosure and opening orientation were changed to simulate the wind environment (meteorological parameter setting was the same as in Table 2). The wind speed simulation results of the squares are shown in Figure 12. It can be seen that when the 
squares were in the same location, the wind conditions of the squares with buildings enclosed on the north and south sides were better than the squares without buildings, and the north-side-enclosed buildings were slightly better than the south-side-enclosed buildings when there was a building enclosure on the north or south side, respectively. The inside wind conditions of the block were better than the entrance at both ends of the block, because the enclosing degree was relatively high when it was set in the middle, and the entrance at both ends of the block would be subject to two side streets. Furthermore, the square that was located in the middle of the block along with the building on the north side and formed a three-side-enclosed layout (case 5) showed the best conditions of the wind environment, with uniform air velocity distribution and its maximum wind speed being significantly smaller than in the other cases.
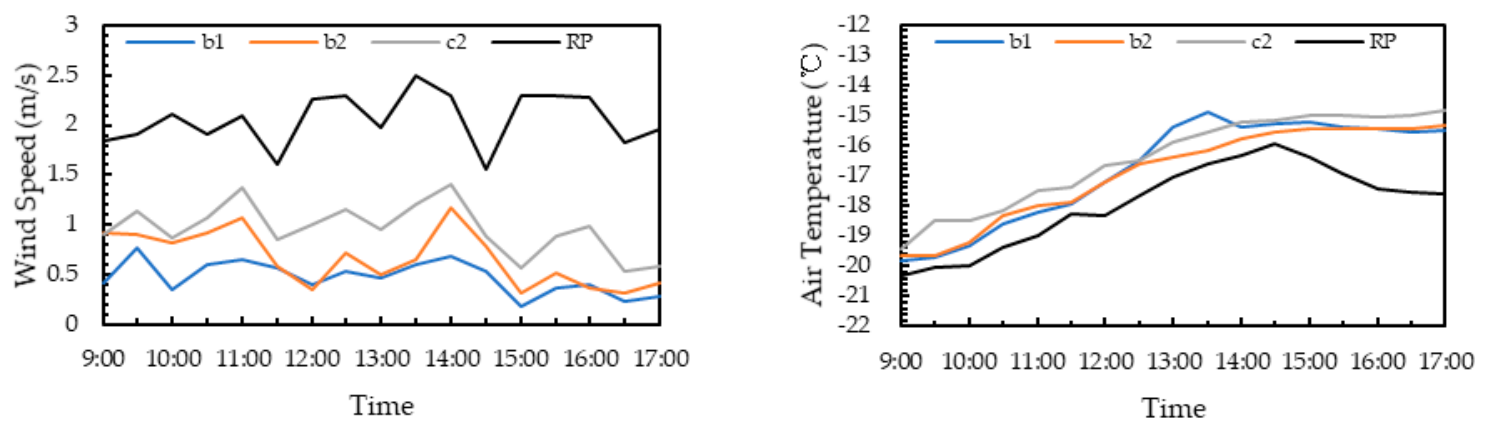

Figure 11. The hourly comparison of measured wind speed and air temperature on the square and adjacent streets.

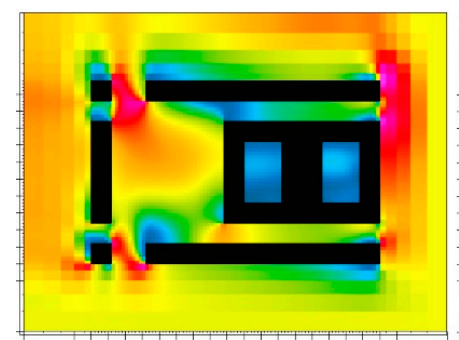

case 1

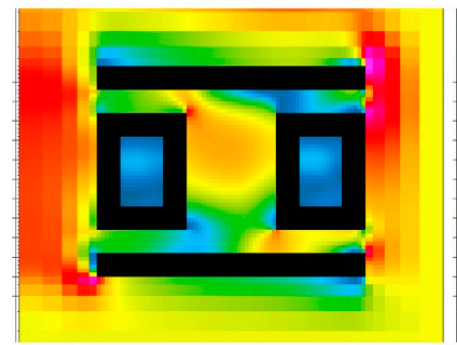

case 4

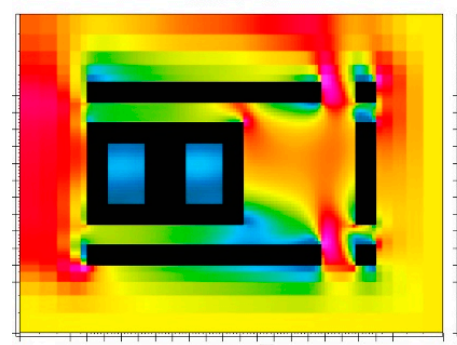

case 7

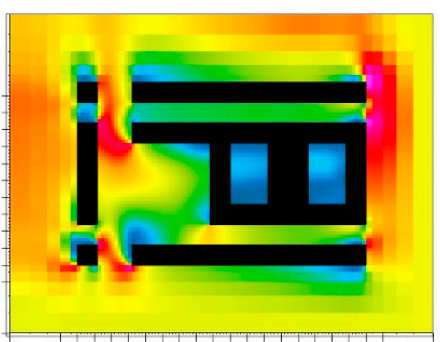

case 2

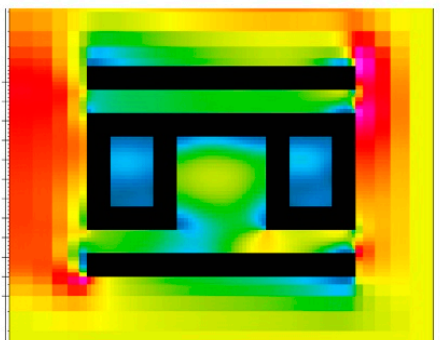

case 5

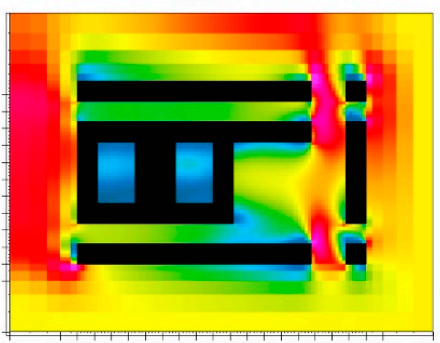

case 8

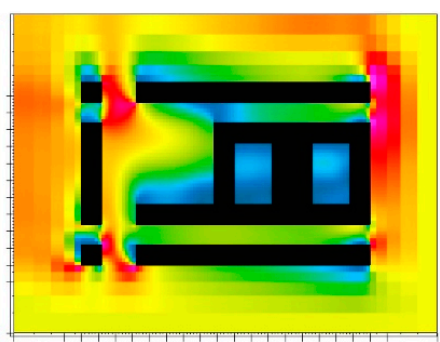

case 3

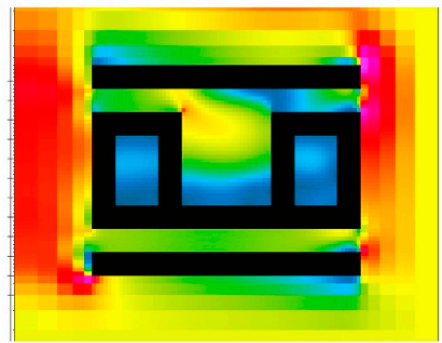

case 6

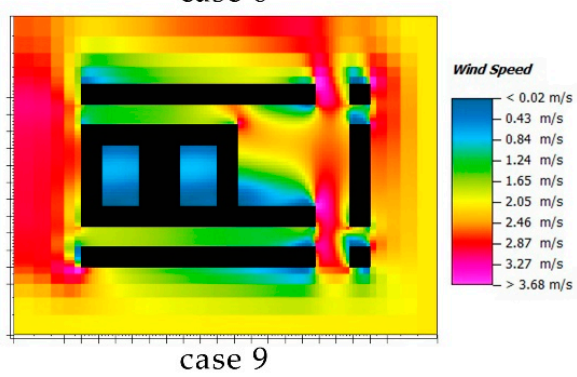

Figure 12. The wind speed simulation results of the squares in different degrees of enclosure and opening orientation. 
In summary, in the case of same scale, the higher degree of enclosure of the square, the lower the wind speed inside. In addition, the opening orientation of the square had a certain influence on the wind environment when the degree of enclosure was the same. The two squares in the Chinese-Baroque historic conservation area in Harbin were relatively closed (three-side-enclosed) squares along the street, all located inside the block and surrounded by buildings on the north side. The wind speed inside the space was relatively low in a relatively stable wind environment, reflecting the climate adaptability of the central square in the Chinese-Baroque historic conservation area.

\section{Conclusions}

The Chinese-Baroque historic conservation area demonstrates the construction techniques of the city's past inhabitants adapting to nature in the architectural design and block layout. This paper extracted and analyzed the climate adaptability of the block through field measurements and numerical simulations that showed three main aspects of the climate adaptation technology of the block:

Comparing the Chinese-Baroque block with the modern city block, it was found that the wind speed change in the Chinese-Baroque block was relatively gentle. The average daily wind speed was $1.09-1.61 \mathrm{~m} / \mathrm{s}$ lower than at the reference point and the average daily air temperature was $0.49-1.49^{\circ} \mathrm{C}$ higher than at the reference point. This showed that the layout of the block allowed the block to obtain a relatively stable microclimate environment in winter and could reduce heat loss, in addition to keeping out the cold by effectively resisting the cold wind from permeating inside. Therefore, in the design of group layout, buildings can be compact and concentrated and buildings can be built along the block to form semienclosed or enclosed spaces to meet the winter windproof and coldproof needs.

Comparing the courtyards with the reference point, the courtyards' daily average wind speed was $1.12-1.61 \mathrm{~m} / \mathrm{s}$ lower and the daily average temperature was $0.49-1.33{ }^{\circ} \mathrm{C}$ higher. The courtyards had a certain performance of wind and cold resistance. Through the simulation, it was found that the rectangular courtyards with a higher degree of enclosure had a stronger windproof performance on the same land area. When the courtyard space was enclosed by four sides and the courtyard width was same, as the plane aspect ratio was smaller, the maximum wind speed of the inner courtyard was smaller. Overall, the smaller the courtyard area, the stronger the resistance to the wind obtained. The rectangular courtyard in this block was predominant and the courtyard area was generally less than $500 \mathrm{~m}^{2}$, so it had a better windproof performance. Therefore, when choosing the courtyard form, the occlusion of the dominant wind direction in winter should be considered. If the wind direction is changeable and strong windproof capability is required, a rectangular courtyard enclosed by four sides is a good choice.

Comparing the squares with the reference point, the daily average wind speeds of the two squares in the block were $1.58 \mathrm{~m} / \mathrm{s}$ and $1.39 \mathrm{~m} / \mathrm{s}$ lower, respectively, and the daily average temperature was $1.14{ }^{\circ} \mathrm{C}$ and $1.02{ }^{\circ} \mathrm{C}$ higher, respectively. They had a good performance in cold resistance. Through the simulation, it was found that, at the same scale, the higher the degree of enclosure of the square, the lower the internal wind speed; at the same degree of enclosure, the opening of the square had a certain influence on the wind environment. The enclosure degree of the two squares in the block was high, and when it was the predominant wind direction, the south-oriented opening could be a better choice. In the tested dominant wind direction, the square space should be avoided at the eastern entrance of the block when there is no building enclosure on either side of the north and south.

This paper studies the Chinese-Baroque historic conservation area by using climate as a breakthrough point. The climate data and the microclimate relationship of different spaces can provide basic data for the future improvement of such blocks. In the meantime, as one of the blocks in the severe cold area, the block provides a reference case for the study of climate adaptability in severe cold areas.

In conclusion, the Chinese-Baroque historic conservation area has taken advantage of climate-adaptive construction techniques to reduce the adverse effects of harsh winter weather conditions on the thermal environment in cold regions. It creates a comfortable and pleasant block 
activity space, thus enhancing the vitality of the block. Therefore, the climatic adaptability construction of the Chinese-Baroque historic conservation area is of great reference value for the architectural layout of modern urban blocks in cold weather and the design of outdoor spaces.

Author Contributions: H.J., J.Z., J.K., and S.L. conceived the paper and designed the field measurements and the numerical study; J.Z. and S.L. performed the field measurements; J.Z. performed numerical simulation and analyzed the data; J.Z. wrote the initial draft; H.J., J.Z., J.K., and S.L. revised the paper.

Funding: This research was funded by the National Natural Science Foundation of China, Grant Number 51438005.

Acknowledgments: This work was financially supported by the National Natural Science Foundation of China (Grant Number: 51438005).

Conflicts of Interest: The authors declare no conflict of interest.

\section{References}

1. Skelhorn, C.; Lindley, S.; Levermore, G. The impact of vegetation types on air and surface temperatures in a temperate city: A fine scale assessment in Manchester, UK. Landsc. Urban Plan. 2014, 121, 129-140. [CrossRef]

2. Duan, Z.; Zhao, X.; Zhan, C.; Dong, X.; Chen, H. Energy saving potential of a counter-flow regenerative evaporative cooler for various climates of China: Experiment-based evaluation. Energy Build. 2017, 148, 199-210. [CrossRef]

3. Johansson, E.; Grundström, K.; Rosenlund, H. Street canyon microclimate in traditional and modern neighbourhoods in a hot dry climate-A case study in Fez, Morocco. Plea Assoc. 2001, 2, 661-665.

4. Johansson, E. Influence of urban geometry on outdoor thermal comfort in a hot dry climate: A study in Fez, Morocco. Build. Environ. 2006, 41, 1326-1338. [CrossRef]

5. Indraganti, M. Understanding the climate sensitive architecture of Marikal, a village in Telangana region in Andhra Pradesh, India. Build. Environ. 2010, 45, 2709-2722. [CrossRef]

6. Dili, A.S.; Naseer, M.A.; Varghese, T.Z. Passive environment control system of Kerala vernacular residential architecture for a comfortable indoor environment: A qualitative and quantitative analyses. Energy Build. 2010, 42, 917-927. [CrossRef]

7. Nasrollahi, N.; Hatami, M.; Khastar, S.R.; Taleghani, M. Numerical evaluation of thermal comfort in traditional courtyards to develop new microclimate design in a hot and dry climate. Sustain. Cities Soc. 2017, 35, 449-467. [CrossRef]

8. Cheng, Y.Y.; Guo, W.H. An Analysis of the Principles That Create the Microclimate of Courtyards in Vernacular Houses Surrounded by Embankment. Archit. J. 2015, 1, 70-73.

9. Fan, R.B.; Li, H.Y.; Yuan, D. Research on ecological mico-climate in historic district based on ecotect: The case of Sanxuejie Historic District in Xi an. Huazhong Archit. 2016, 34, 100-105.

10. Wan, T.; Hou, M.Q. Analysis on spatial wind environment of Chinese Baroque architectural complex in Harbin. Shanxi Archit. 2016, 42, 7-9. [CrossRef]

11. Zeng, Y.L.; Dong, L. Research on Summer Microclimate Environment of Pedestrian Street: A Case Study of the Kuan Zhai Alley. Chin. Landsc. Archit. 2014, 8, 92-96.

12. Chinese-Baroque. Available online: https://baike.baidu.com/item/\%E4\%B8\%AD\%E5\%8D\%8E\%E5\%B7\%B4\% E6\%B4\%9B\%E5\%85\%8B/6461582?fr=aladdin\#reference-[1]-1899813-wrap (accessed on 11 September 2018).

13. Aerial China. Available online: http://jishi.cctv.com/special/djsb/hpzg/index.shtml (accessed on 11 September 2018).

14. Wang, Y.; Liu, D.P.; Lu, T. Oppugning about Chinese-Baroque architecture in Harbin. Huazhong Archit. 2006, 185-188. [CrossRef]

15. Wan, N.; Pan, W.; Lv, H.R. Protection and renovation program of Chinese-Baroque Historic Block in Harbin. City Plan. Rev. 2011, 6, 86-90.

16. Lei, S.; Feng, N. The appreciation of architectural art of Chinese Baroque in Harbin. Chin. Overseas Archit. 2016, 8, 40-42.

17. Wang, Y.; Hou, Y.B.; Lu, T. Preliminary Research on the "Daowai Pattern" in the Process of the Transformation to Modernization of Chinese Traditional Architecture. Huazhong Archit. 2007, 170-174. [CrossRef] 
18. Liang, W.N. Chinese-Baroque-A unique modern style of architecture in Harbin. J. Harbin Univ. Civ. Eng. Archit. 2001, 34, 98-102.

19. Liang, X.; Zhao, L.H. Research on Chinese Baroque of Harbin Daowai District. Shanxi Archit. 2016, 42, 7-8. [CrossRef]

20. Zhang, X.N.; Li, H.L.; Zhu, Y. Enclosed courtyard generating space form: The regeneration of Chinese Baroque History District in Daowai of Harbin. Urban. Archit. 2018, 4, 120-123.

21. Levoshko, S.; Kirichkov, I. Tourist Quarter “Chinese-Baroque” of Dao Way District in Harbin City: Experience, problems and perspectives of renovation. MATEC Web Conf. 2016, 73, 06003. [CrossRef]

22. Ru, Y.L.; Ma, Q.M. Research on Sustainable Development of Baroque Architecture Community in China. Huazhong Archit. 2010, 28, 158-160. [CrossRef]

23. Han, D.; Yao, K.Y.; Liu, C.L. The Renaissance Studies of Harbin Daowai District, South Two, South Three Street Yard Space. Chin. Overseas Archit. 2012, 12, 52-54.

24. Hourly Observation of Ground Meteorological Stations in China. Available online: http://data.cma.cn/ data/detail/dataCode/A.0012.0001.html (accessed on 2 January 2018).

25. Bruse, M.; Fleer, H. Simulating surface-plantair interactions inside urban environments with a threedimensional numerical model. Environ. Modell. Softw. 1998, 13, 373-384. [CrossRef]

26. Ng, E.; Chen, L.; Wang, Y.; Yuan, C. A study on the cooling effects of greening in a high-density city: An experience from Hong Kong. Build. Environ. 2012, 47, 256-271. [CrossRef]

27. Andreou, E.; Axarli, K. Investigation of urban canyon microclimate in traditional and contemporary environment. Experimental investigation and parametric analysis. Renew. Energy 2012, 43, 354-363. [CrossRef]

28. Li, K.M.; Zhao, L.H. Research on Thermal Environment of Village in Pearl River Delta Region. Appl. Mech. Mater. 2013, 368-370. [CrossRef]

29. Jin, H.; Liu, Z.; Jin, Y.; Kang, J.; Liu, J. The Effects of Residential Area Building Layout on Outdoor Wind Environment at the Pedestrian Level in Severe Cold Regions of China. Sustainability 2017, 9, 2310. [CrossRef]

(c) 2018 by the authors. Licensee MDPI, Basel, Switzerland. This article is an open access article distributed under the terms and conditions of the Creative Commons Attribution (CC BY) license (http:/ / creativecommons.org/licenses/by/4.0/). 